
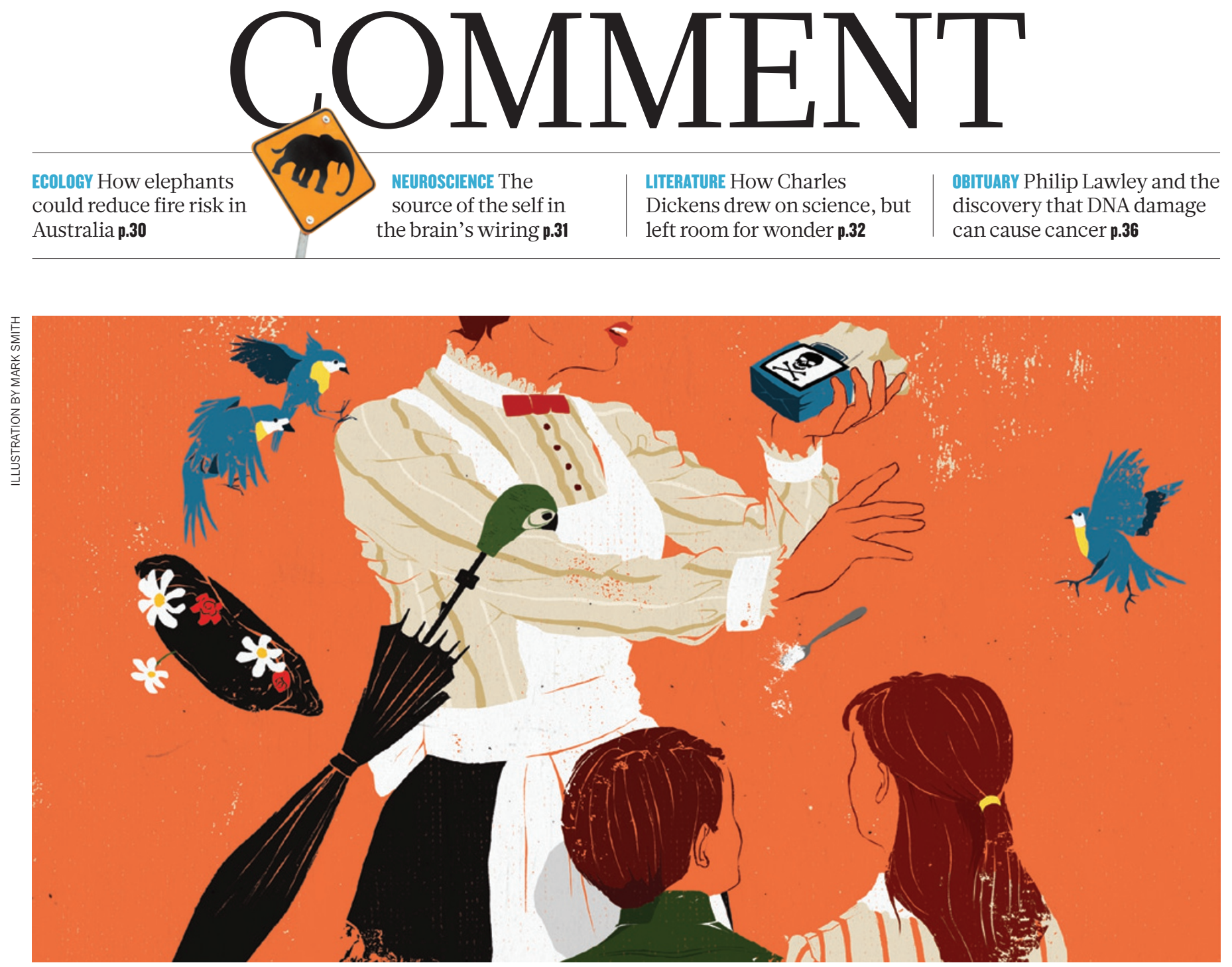

\title{
The toxic truth about sugar
}

Added sweeteners pose dangers to health that justify controlling them like alcohol, argue Robert H. Lustig, Laura A. Schmidt and Claire D. Brindis.

$\mathrm{L}$ ast September, the United Nations declared that, for the first time in human history, chronic non-communicable diseases such as heart disease, cancer and diabetes pose a greater health burden worldwide than do infectious diseases, contributing to 35 million deaths annually.

This is not just a problem of the developed world. Every country that has adopted the Western diet - one dominated by low-cost, highly processed food - has witnessed rising rates of obesity and related diseases. There are now 30\% more people who are obese than who are undernourished. Economic development means that the populations of low- and middle-income countries are living longer, and therefore are more

\section{SUMMARY \\ - Sugar consumption is linked to a rise in non-communicable disease \\ - Sugar's effects on the body can be similar to those of alcohol \\ - Regulation could include tax, limiting sales during school hours and placing age limits on purchase}

susceptible to non-communicable diseases; $80 \%$ of deaths attributable to them occur in these countries.

Many people think that obesity is the root cause of these diseases. But $20 \%$ of obese people have normal metabolism and will have a normal lifespan. Conversely, up to $40 \%$ of normal-weight people develop the diseases that constitute the metabolic syndrome: diabetes, hypertension, lipid problems, cardiovascular disease and non-alcoholic fatty liver disease. Obesity is not the cause; rather, it is a marker for metabolic dysfunction, which is even more prevalent.

The UN announcement targets tobacco, alcohol and diet as the central risk factors in non-communicable disease. Two of these three - tobacco and alcohol - are regulated by governments to protect public health, leaving one of the primary culprits behind this worldwide health crisis unchecked. Of course, regulating food is more 
complicated - food is required, whereas tobacco and alcohol are non-essential consumables. The key question is: what aspects of the Western diet should be the focus of intervention?

In October 2011, Denmark chose to tax foods high in saturated fat, despite the fact that most medical professionals no longer believe that fat is the primary culprit. But now, the country is considering taxing sugar as well - a more plausible and defensible step. Indeed, rather than focusing on fat and salt - the current dietary 'bogeymen' of the US Department of Agriculture (USDA) and the European Food Safety Authority - we believe that attention should be turned to 'added sugar', defined as any sweetener containing the molecule fructose that is added to food in processing.

Over the past 50 years, consumption of sugar has tripled worldwide. In the United States, there is fierce controversy over the pervasive use of one particular added sugar - high-fructose corn syrup (HFCS). It is manufactured from corn syrup (glucose), processed to yield a roughly equal mixture of glucose and fructose. Most other developed countries eschew HFCS, relying on naturally occurring sucrose as an added sugar, which also consists of equal parts glucose and fructose.

Authorities consider sugar as 'empty calories' - but there is nothing empty about these calories. A growing body of scientific evidence is showing that fructose can trigger processes that lead to liver toxicity and a host of other chronic diseases ${ }^{1}$. A little is not a problem, but a lot kills - slowly (see 'Deadly effect'). If international bodies are truly concerned about public health, they must consider limiting fructose - and its main delivery vehicles, the added sugars HFCS and sucrose - which pose dangers to individuals and to society as a whole.

\section{NO ORDINARY COMMODITY}

In 2003, social psychologist Thomas Babor and his colleagues published a landmark book called Alcohol: No Ordinary Commodity, in which they established four criteria, now largely accepted by the public-health community, that justify the regulation of alcohol - unavoidability (or pervasiveness throughout society), toxicity, potential for abuse and negative impact on society ${ }^{2}$. Sugar meets the same criteria, and we believe that it similarly warrants some form of societal intervention.

First, consider unavoidability. Evolutionarily, sugar was available to our ancestors as fruit for only a few months a year (at harvest time), or as honey, which was guarded by bees. But in recent years, sugar has been added to nearly all processed foods, limiting consumer choice ${ }^{3}$. Nature made sugar hard to get; man made it easy. In many parts of the world, people are consuming an average of more than 500 calories per day from added sugar alone (see 'The global sugar glut').

Now, let's consider toxicity. A growing body of epidemiological and mechanistic evidence argues that excessive sugar consumption affects human health beyond simply adding calories ${ }^{4}$. Importantly, sugar induces all of the diseases associated with metabolic syndrome ${ }^{1,5}$. This includes: hypertension (fructose increases uric acid, which raises blood pressure); high triglycerides and insulin resistance through synthesis of fat in the liver; diabetes from increased liver

"Sugar is
cheap, sugar
tastes good and
sugar sells,
so companies
have little
incentive to
change."
glucose production combined with insulin resistance; and the ageing process, caused by damage to lipids, proteins and DNA through nonenzymatic binding of fructose to these molecules. It can also be argued that fructose exerts toxic effects on the liver that are similar to those of alco$\mathrm{hol}^{1}$. This is no surprise, because alcohol is derived from the fermentation of sugar. Some early studies have also linked sugar consumption to human cancer and cognitive decline.

Sugar also has clear potential for abuse. Like tobacco and alcohol, it acts on the brain to encourage subsequent intake. There are now numerous studies examining the dependence-producing properties of sugar in humans ${ }^{6}$. Specifically, sugar dampens the suppression of the hormone ghrelin, which signals hunger to the brain. It also interferes with the normal transport and signalling of the hormone leptin, which helps to produce the feeling of satiety. And it reduces dopamine signalling in the brain's reward centre, thereby decreasing the pleasure derived from food and compelling the individual to consume more ${ }^{1,6}$.

Finally, consider the negative effects of sugar on society. Passive smoking and drinkdriving fatalities provided strong arguments for tobacco and alcohol control, respectively. The long-term economic, health-care and human costs of metabolic syndrome place sugar overconsumption in the same category ${ }^{7}$. The United States spends $\$ 65$ billion in lost productivity and $\$ 150$ billion on health-care resources annually for morbidities associated with metabolic syndrome. Seventy-five per cent of all US health-care dollars are now spent on treating these diseases and their resultant disabilities. Because about $25 \%$ of military applicants are now rejected for obesity-related reasons, the past three US surgeons general and the chairman of the US Joint Chiefs of Staff have declared obesity a "threat to national security".

\section{HOW TO INTERVENE}

How can we reduce sugar consumption? After all, sugar is natural. Sugar is a nutrient. Sugar is pleasure. So too is alcohol, but in both cases, too much of a good thing is toxic. It may be helpful to look to the many generations of international experience with alcohol and tobacco to find models that work ${ }^{8,9}$. So far, evidence shows that individually focused approaches, such as school-based interventions that teach children about diet and exercise, demonstrate little efficacy. Conversely, for both alcohol and tobacco, there is robust evidence that gentle 'supply side' control strategies which stop far short of all-out prohibition - taxation, distribution controls, age limits - lower both consumption of the product and the accompanying health harms. Successful interventions share a common end-point: curbing availability ${ }^{2,8,9}$.

Taxing alcohol and tobacco products - in the form of special excise duties, value-added taxes and sales taxes - are the most popular and effective ways to

\section{DEADLY EFFECT}

Excessive consumption of fructose can cause many of the same health problems as alcohol.

\begin{tabular}{l|l} 
Chronic ethanol exposure & Chronic fructose exposure \\
Haematological disorders & \\
Electrolyte abnormalities & Hypertension (uric acid) \\
Hypertension & \\
Cardiac dilatation & Myocardial infarction (dyslipidaemia, insulin resistance) \\
Cardiomyopathy & Dyslipidaemia (de novo lipogenesis) \\
\hline Dyslipidaemia & Pancreatitis (hypertriglyceridaemia) \\
\hline $\begin{array}{l}\text { Pancreatitis } \\
\text { Obesity (insulin resistance) }\end{array}$ & Obesity (insulin resistance) \\
\hline Malnutrition & Malnutrition (obesity) \\
\hline Hepatic dysfunction (alcoholic steatohepatitis) & Hepatic dysfunction (non-alcoholic steatohepatitis) \\
\hline Fetal alcohol syndrome & Habituation, if not addiction \\
\hline Addiction &
\end{tabular}

Source: ref. 1 


\section{THE GLOBAL SUGAR GLUT}

Global sugar supply (in the form of sugar and sugar crops, excluding fruit and wine) expressed as calories per person per day, for the year 2007.
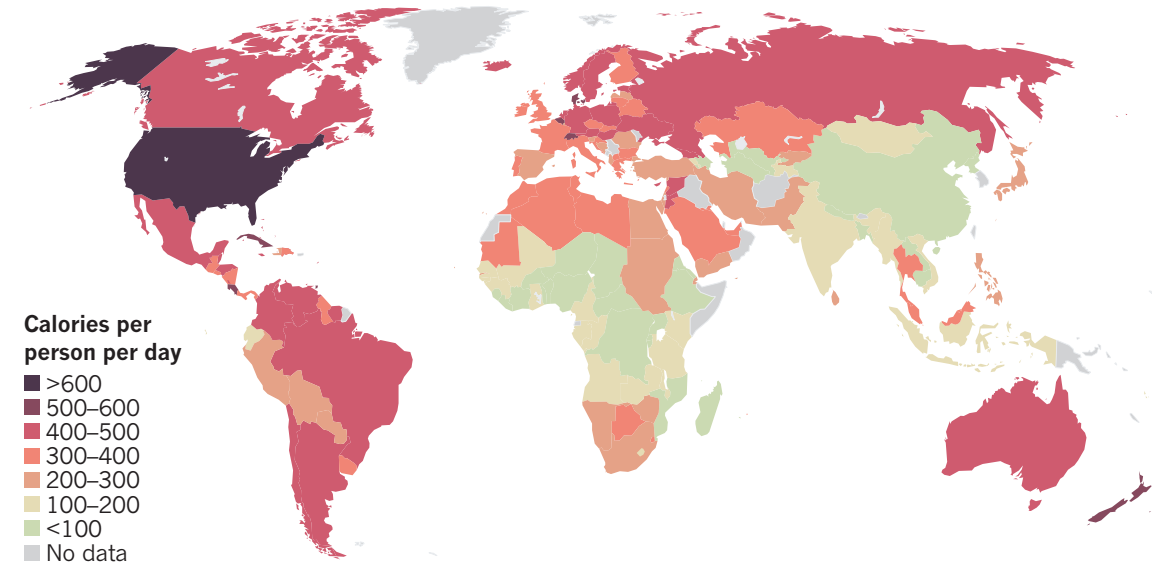

reduce smoking and drinking, and in turn, substance abuse and related harms ${ }^{2}$. Consequently, we propose adding taxes to processed foods that contain any form of added sugars. This would include sweetened fizzy drinks (soda), other sugar-sweetened beverages (for example, juice, sports drinks and chocolate milk) and sugared cereal. Already, Canada and some European countries impose small additional taxes on some sweetened foods. The United States is currently considering a penny-per-ounce soda tax (about 34 cents per litre), which would raise the price of a can by $10-12$ cents. Currently, a US citizen consumes an average of 216 litres of soda per year, of which 58\% contains sugar. Taxing at a penny an ounce could provide annual revenue in excess of $\$ 45$ per capita (roughly $\$ 14$ billion per year); however, this would be unlikely to reduce total consumption. Statistical modelling suggests that the price would have to double to significantly reduce soda consumption so a $\$ 1$ can should cost $\$ 2$ (ref. 10).

Other successful tobacco- and alcoholcontrol strategies limit availability, such as reducing the hours that retailers are open, controlling the location and density of retail markets and limiting who can legally purchase the products ${ }^{2,9}$. A reasonable parallel for sugar would tighten licensing requirements on vending machines and snack bars that sell sugary products in schools and workplaces. Many schools have removed unhealthy fizzy drinks and candy from vending machines, but often replaced them with juice and sports drinks, which also contain added sugar. States could apply zoning ordinances to control the number of fast-food outlets and convenience stores in low-income communities, and especially around schools, while providing incentives for the establishment of grocery stores and farmer's markets.
Another option would be to limit sales during school operation, or to designate an age limit (such as 17) for the purchase of drinks with added sugar, particularly soda. Indeed, parents in South Philadelphia, Pennsylvania, recently took this upon themselves by lining up outside convenience stores and blocking children from entering them after school. Why couldn't a public-health directive do the same?

\section{THE POSSIBLE DREAM}

Government-imposed regulations on the marketing of alcohol to young people have been quite effective, but there is no such approach to sugar-laden products. Even so, the city of San Francisco, California, recently banned the inclusion of toys with unhealthy meals such as some types of fast food. A limit - or, ideally, ban - on television commercials for products with added sugars could further protect children's health.

Reduced fructose consumption could also be fostered through changes in subsidization. Promotion of healthy foods in US low-income programmes, such as the Special Supplemental Nutrition Program for Women, Infants and Children and the Supplemental Nutrition Assistance Program (also known as the food-stamps programme) is an obvious place to start. Unfortunately, the petition by New York City to remove soft drinks from the food-stamp programme was denied by the USDA.

Ultimately, food producers and distributors must reduce the amount of sugar added to foods. But sugar is cheap, sugar tastes good and sugar sells, so companies have little incentive to change. Although one institution alone can't turn this juggernaut around, the US Food and Drug Administration could "set the table" for change $e^{8}$. To start, it should consider removing fructose from the Generally Regarded as Safe
(GRAS) list, which allows food manufacturers to add unlimited amounts to any food. Opponents will argue that other nutrients on the GRAS list, such as iron and vitamins $A$ and $\mathrm{D}$, can also be toxic when over-consumed. However, unlike sugar, these substances have no abuse potential. Removal from the GRAS list would send a powerful signal to the European Food Safety Authority and the rest of the world.

Regulating sugar will not be easy particularly in the 'emerging markets' of developing countries where soft drinks are often cheaper than potable water or milk. We recognize that societal intervention to reduce the supply and demand for sugar faces an uphill political battle against a powerful sugar lobby, and will require active engagement from all stakeholders. Still, the food industry knows that it has a problem - even vigorous lobbying by fastfood companies couldn't defeat the toy ban in San Francisco. With enough clamour for change, tectonic shifts in policy become possible. Take, for instance, bans on smoking in public places and the use of designated drivers, not to mention airbags in cars and condom dispensers in public bathrooms. These simple measures - which have all been on the battleground of American politics - are now taken for granted as essential tools for our public health and well-being. It's time to turn our attention to sugar.

Robert H. Lustig is in the Department of Pediatrics and the Center for Obesity Assessment, Study and Treatment at the University of California, San Francisco, California 94143, USA. Laura A. Schmidt and Claire D. Brindis are at the Clinical and Translational Science Institute and the Philip R. Lee Institute for Health Policy Studies, University of California, San Francisco, California 94118, USA. e-mail:rlustig@peds.ucsf.edu

1. Lustig, R. H. J. Am. Diet. Assoc. 110, 1307-1321 (2010)

2. Babor, T. et al. Alcohol: No Ordinary Commodity: Research and Public Policy (Oxford Univ. Press, 2003).

3. Vio, F. \& Uauy, R. in Food Policy for Developing Countries: Case Studies (eds Pinstrup-Andersen, P. \& Cheng, F.) No. 9-5 (2007); available at http:// go.nature.com/prisk4

4. Joint WHO/FAO Expert Consultation. Diet, Nutrition and the Prevention of Chronic Diseases WHO Technical Report Series 916 (WHO; 2003).

5. Tappy, L., Lê, K. A., Tran, C. \& Paquot, N. Nutrition 26, 1044-1049 (2010).

6. Garber, A. K. \& Lustig, R. H. Curr. Drug Abuse Rev. 4, 146-162 (2011).

7. Finkelstein, E. A., Fiebelkorn, I. C. \& Wang, G. Health Aff. W3 (suppl.), 219-226 (2003).

8. Engelhard, C. L., Garson, A. Jr \& Dorn, S. Reducing Obesity: Policy Strategies from the Tobacco Wars (Urban Institute, 2009); available at http://go.nature.com/w4o5uk

9. Room, R., Schmidt, L. A., Rehm, J. \& Mäkela P. Br. Med. J. 337, a2364 (2008).

10.Sturm, R., Powell L. M., Chriqui, J. F. \& Chaloupka, F. J. Health Aff. 29, 1052-1058 (2010). 